\title{
ИССЛЕДОВАНИЕ ВЗАИМОДЕЙСТВИЙ В СИСТЕМЕ БЕЛОК - СОЛИ ЦИНКА - ОРГАНИЧЕСКИЙ ДУБИТЕЛЬ
}

\author{
В. И. Чурсин, П. М. Магомедова
}

\begin{abstract}
ВЯЧЕСЛАВ ИВАНОВИЧ ЧУРСИН - д.т.н., профессор, заведуюший кафедрой технологии кожи и меха Российского государственного университета им. A.H. Kосыгина.E-mail: mars8848@rambler.ru.
\end{abstract}

\begin{abstract}
П.М. МАГОМЕДОВА - кафедра технологии кожи и меха Российского государственного университета им. А.Н. Косыгина.
\end{abstract}

Российский государственный университет им. А.Н. Косыгина, 117997, Москва, ул. Садовническая, 33.

\begin{abstract}
В работе рассматривается возможность использования альтернативной соединениям хрома системы комбинированного дубления включающей соли ичинка и органический дубитель. Методом ИК-спектроскопии идентифицирована структура органического дубителя, синтезированного на основе формальдегида и этаноламина. Изучено влияние солей иинка на вязкость и значение рН раствора дубителя. Показана различная способность ацетата иинка и сульфата иинка взаимодействовать с органическим дубителем с образованием комплексных соединений. Полученные результаты подтверждены методом фотометрии. Предложена вероятностная структурная формула образовавщегося комплекса. Методом кондуктометрии исследовано изменение электропроводности водных растворов ацетата и сульфата цинка в присутствии аминокислот с различными функииональными группами в боковом радикале. Показано влияние аниона соли на способность к образованию комплексов с различной координацией лигандов к иентральному атому иинка в зависимости от вида аминокислоты. По величине отклонения экспериментальной зависимости электропроводности от расчетных аддитивных значений при различных соотночениях аминокислота-соль иинка определен максимальный выход комплекса. Установлен положительный эффект предварительной обработки желатина органическим дубителем на сорбиию солей иинка из водных растворов через целлюлозную мембрану. Показано, что сульфат иинка более интенсивно сорбируется желатином после обработки её органическим дубителем. Дана интерпретачия этого эффекта. Полученные результаты подтверждень при проведении реального процесса дубления, в котором зафиксировано увеличение гидротермической устойчивости коллагена дермы при последовательной обработке органическим дубителем и солями циинка.
\end{abstract}

Ключевые слова: взаимодействие, органический дубитель, соли цинка, комплексные соединения, желатин, аминокислоты, электропроводность.

\section{RESEARCH INTERACTIONS IN THE SYSTEM PROTEIN - ZINC SALTS - ORGANIC TANNING AGENT}

\author{
V.I. Chursin, P.M. Magomedova
}

Moscow State University of Design and Technology, 117997, Moscow, ul. Sadovnicheskaya 33

The paper considers the possibility of using an alternative to chromium compounds system of combined tanning comprising zinc salts and an organic tanning agent. Using IR spectroscopy, the structure of an organic tan- 
ning agent synthesized based on formaldehyde and ethanolamine was identified. The effect of zinc salts on the viscosity and $\mathrm{pH}$ of a tanning solution was studied. The different ability of zinc acetate and zinc sulfate to interact with an organic tanning agent with the formation of complex compounds is shown. The results are confirmed by photometry. A probabilistic structural formula of the resulting complex is proposed. The conductometric method was used to study the change in the electrical conductivity of aqueous solutions of zinc acetate and sulfate in the presence of amino acids with various functional groups in the side radical. The effect of the salt anion on the ability to form complexes with different coordination of ligands to the central zinc atom depending on the type of amino acid is shown. The maximum yield of the complex is determined from the deviation of the experimental dependence of electrical conductivity from the calculated additive values at various ratios of amino acid-zinc salt. The positive effect of pretreatment of gelatin with an organic tanning agent on the sorption of zinc salts from aqueous solutions through a cellulose membrane has been established. It was shown that zinc sulfate is more intensively sorbed by gelatin after treatment with an organic tanning agent. An interpretation of this effect is given. The obtained results were confirmed during a real tanning process, in which an increase in the hydrothermal stability of dermal collagen during sequential treatment with an organic tannin and zinc salts was recorded.

Keywords: interaction, organic tanning agent, zinc salts, complex compounds, gelatin, amino acids, electrical conductivity.

Традиционные технологии дубления в производстве кожи и меха основаны на использовании дубящих соединений хрома. Современные требования к технологическим процессам кожевенного производства учитывают не только такие необходимые характеристики, как качество продукции, длительность обработки, энергозатраты, но и в первую очередь экологичность технологии. Хромовое дубление позволяет получить кожу с высокими показателями гидротермической устойчивости, хорошими прочностными свойствами, необходимыми для изготовления изделий упруго-пластическими характеристиками. Более $85 \%$ мирового производства кож составляют кожи, выработанные с использованием дубящих соединений хрома [13].

Проблема заключается в том, что в отработанных растворах после дубления, содержание солей хрома составляет от 5 до 7 г/л, считая на оксид хрома $[4,5]$. Присутствие в сточных водах соединений трехвалентного хрома $\left(\mathrm{Cr}^{3+}\right)$, из которых, при определенных условиях, могут образовываться и соли шестивалентного хрома $\left(\mathrm{Cr}^{6+}\right)$, относящиеся к канцерогенным соединениям, требует значительных технологических и финансовых затрат на их очистку. Именно этим обусловлен значительный интерес к разработке новых экологически приемлемых технологий дубления кожи. В работах $[1,2$, $4,6,7]$ в качестве альтернативы дубящим соединениям хрома рассматриваются растительные дубители, альдегиды, оксазолидины, соли титана, циркония, алюминия.

Растительные дубители по своей природе относятся к полифенольным соединениям. Определение биоразлагаемости растительных экстрактов показало, что эти соединения трудно подвергают- ся биодеградации и представляют проблему при очистке стоков $[4,6]$.

Альдегидные дубители, несмотря на относительно более мягкие требования к содержанию их в сточных водах, не обеспечивают комплекс качественных показателей готовой кожи, по сравнению с хромовым дублением.

Дубящие соединения титана, алюминия, циркония, а также их комбинации не позволяют получить кожу с требуемыми показателями термостойкости, мягкости, эластичности, а технология их применения усложняет процесс дубления, что приводит к дополнительным финансовым затратам $[4,8]$.

Наиболее перспективным направлением в совершенствовании процесса дубления представляется использование реакционноспособных органических соединений, которые при взаимодействии с аминогруппами белка обеспечивают образование межмолекулярных связей в структуре коллагена, и позволяют повысить гидротермическую устойчивость кожи до $80-85^{\circ} \mathrm{C}$. Возможность использования таких соединений в процессе дубления представлена в работах $[4,6,7,9]$. Также отмечена положительная роль соединений цинка, которые вводили в обрабатывающий раствор перед дублением органическими соединениями. Цинк относится к нетоксичным соединениям допустимое содержание цинка в сточных водах в 2 раза выше, чем $\mathrm{Cr}^{3+}$, и в 20 раз выше, чем $\mathrm{Cr}^{6+}[10]$. При выборе солей цинка принимали во внимание их способность образовывать хелатные комплексные соединения с кислородсодержащими соединениями, аминокислотами и полипептидами [11].

В то же время следует подчеркнуть, что процесс дубления в присутствии указанных компо- 
нентов недостаточно изучен и требует проведения дополнительных исследований, которые позволят раскрыть механизм взаимодействия дубящих соединений с белком дермы. Целью настоящей работы было исследование взаимодействия в системе белок - органический дубитель соли цинка.

\section{Методика эксперимента}

В качестве органического дубителя использовали Ортан, синтезированный на основе формальдегида и этаноламина $[7,9]$. Взаимодействие сульфата цинка семиводного и ацетата цинка двухводного с дубителем Ортан исследовали методом изомолярных серий. Использовали водные растворы солей с концентрацией $1 \%$. Все измерения проводили при $20 \pm 0,1{ }^{\circ} \mathrm{C}$. Сорбцию дубителей из растворов проводили с использованием трубчатой целлюлозной мембраны D 9527-100FT диаметром 43 мм (Sicma). В модельных экспериментах использовали $1 \%$ раствор пищевого желатина (ГОСТ 11293-89). Относительную вязкость растворов и их смесей измеряли на капиллярном вискозиметре ВПЖ-2, оптическую плотность определяли на спектрофотометре ПЭ-5400 УФ в кюветах с толщиной поглощающего слоя 1 см. Значение $\mathrm{pH}$ растворов контролировали с помощью ио- номера 150МИ. Электропроводность измеряли на кондуктометре COM-100 (HM-Digital). В качестве объектов исследования, моделирующих структуру белка, были выбраны аминокислоты с различными боковыми радикалами, такими как аминометильный в лизине, амидометильный в аспарагине, карбоксиметильный в аспарагиновой кислоте.

\section{Результаты и их обсуждение}

Состав и строение органического дубителя Ортан устанавливали методом ИК-спектроскопии. ИК спектр дубителя представлен на рис. 1.

При анализе спектра следует выделить сильную полосу при $1120 \mathrm{~cm}^{-1}$, характерную для валентных колебаний $\mathrm{C}-\mathrm{O}$. На спектре идентифицирована сильная и широкая полоса в области 3350 $3500 \mathrm{~cm}^{-1}$, относящаяся к валентным колебаниям группы $\mathrm{OH}$, а также к асимметричным и симметричным валентным колебаниям группы $\mathrm{N}-\mathrm{H}$, характерным для вторичных аминов. Поглощение в области 2870-2943 cм$^{-1}$ соответствует валентным колебаниям групп С-H. Сильная полоса валентных колебаний групп $\mathrm{C}-\mathrm{N}$ проявляется при частоте $1321 \mathrm{~cm}^{-1}$. Деформационные колебания группы $\mathrm{N}-\mathrm{H}$ зафиксированы при $1650 \mathrm{~cm}^{-1}$, а группам C-N в дубителе соответствуют валентные колебания

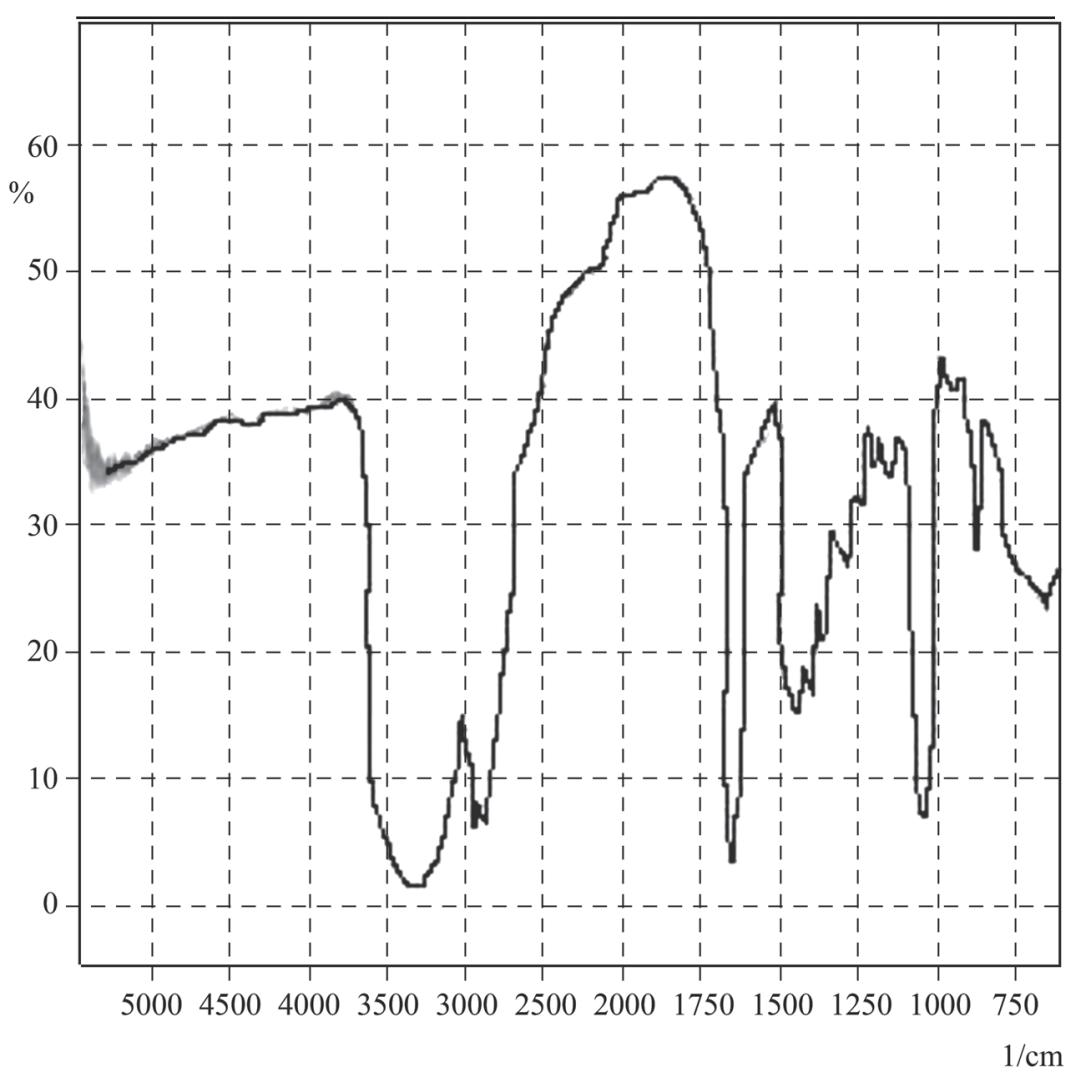

Рис. 1. ИК-спектр органического дубителя Ортан 
при $1360 \mathrm{~cm}^{-1}$. Предположительная формула дубителя $\mathrm{HO}_{2} \mathrm{HC}_{2} \mathrm{HCHNCH}_{2} \mathrm{NHCH}_{2} \mathrm{CH}_{2} \mathrm{OH}$, определенная на основе результатов ИК-спектроскопии, подтверждена данными, полученными при анализе близких по химическому составу соединений [12].

\section{Взаимодействие в системе}

соли цинка - органический дубитель

Взаимодействие в системе соли цинка органический дубитель исследовали методом изомолярных серий по изменению вязкости и значений $\mathrm{pH}$ растворов и отклонению этих значений от расчетных (аддитивных). Анализ представленных на рис. 2 зависимостей показывает, что при взаимодействии дубителя с ацетатом цинка вязкость раствора возрастает, достигая максимальных значений при соотношении ацетат цинка/дубитель равном 50/50. При этом же соотношении можно наблюдать излом на зависимости значений $\mathrm{pH}$. Такое смещение значений $\mathrm{pH}$ является характерным для процесса комплексообразования [11, 13]. Отсутствие различий в определяемых показателях, зафиксированных через 24 часа после смешения компонентов, позволяет сделать вывод, что образование комплексов происходит достаточно быстро.

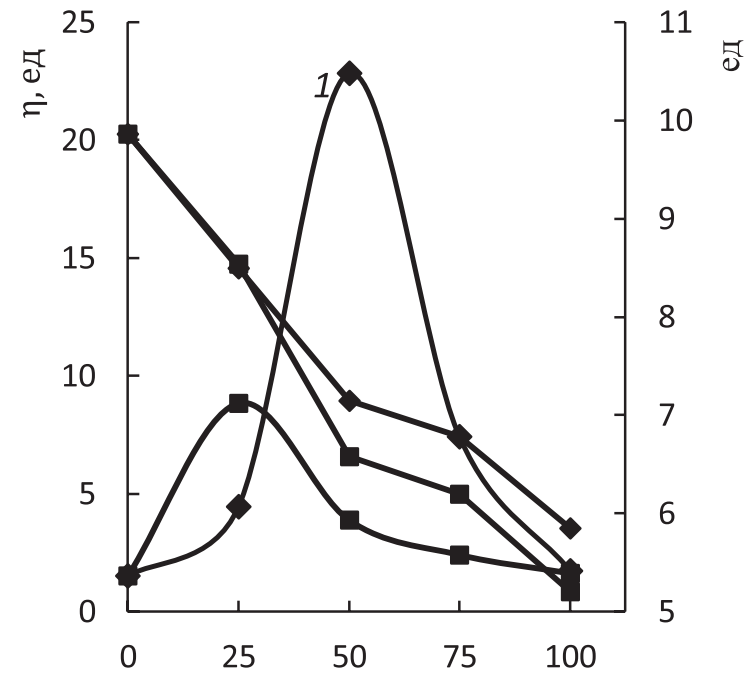

Рис.2. Зависимость вязкости $\boldsymbol{\eta}(1,2)$ и значения рН растворов $(3,4)$ от массовойдоли т ацетата цинка

$(1,3)$ и сульфата цинка $(2,4)$ в дубителе Ортан

Для растворов сульфата цинка и дубителя максимальная вязкость зафиксирована при соотношении соответственно равном 25/75. При этом с течением времени наблюдается снижение вязкости, что может свидетельствовать о неустойчивости образовавшегося комплекса. Следует обратить внимание на то, что и в данном эксперименте излом на зависимости $\mathrm{pH}$ от состава соответствует отношению сульфат цинка/дубитель равному 50/50. По аналогии с механизмом реакции, предложенным в работе [14], образование комплекса может происходить в результате координации к цинку атома азота и кислорода метилольной группы дубителя по схеме:

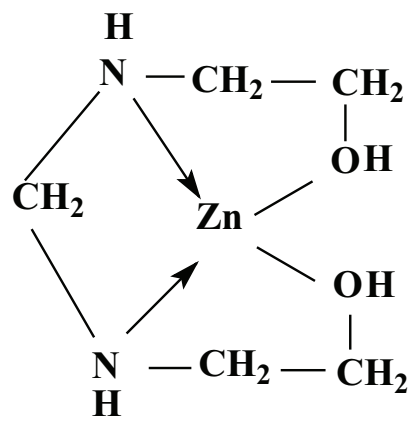

На рис. 3 представлены результаты определения оптической плотности растворов солей цинка в присутствии дубителей в зависимости от их соотношения. Из представленных результатов следует, что максимум оптической плотности раствора наблюдается при соотношении ацетат цинка/дубитель равном 50/50 и сульфат цинка/дубитель 25/75. Экспериментально установлено, что с течением времени, в растворах дубителей в присутствии солей цинка наблюдается разделение фаз, при этом нижний слой представляет собой сметанообразную массу, а верхний слой прозрачную жидкость, что также свидетельствует в пользу образования комплексов.

О взаимодействии солей цинка с дубителем можно судить по отсутствию цинка в надосадочной жидкости при массовой доле соли цинка в сме-

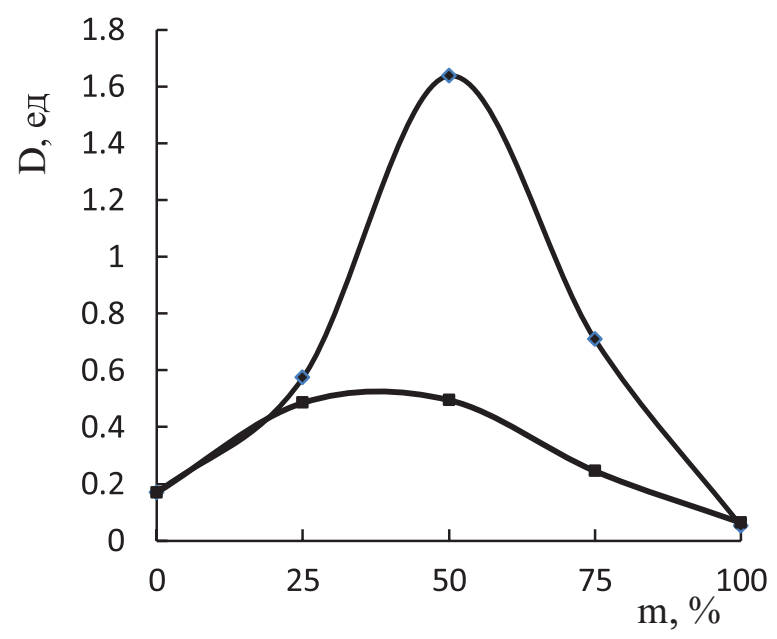

Рис. 3. Влияние массовой доли ацетата цинка (1) и сульфата цинка (2) на оптическую плотность раствора дубителя 
си с дубителем $50 \%$ и $75 \%$, определенному по отрицательной качественной реакции с гексацианоферратом калия [15].

Экспериментальные данные (рис. 2, 3) свидетельствуют о том, что процесс комплексообразования в системе дубитель соль цинка, в случае сульфата начинается при массовой доле сульфата цинка менее чем $25 \%$. По-видимому, причину этого следует искать в меньшем сродстве к иону цинка сульфатного лиганда, который легче может быть вытеснен из внутренней сферы комплекса молекулой дубителя. Максимальный выход комплекса в системе дубитель - ацетат цинка наблюдается при массовой доле соли цинка 50 \% и, можно предположить, образование в этом случае разнолигандных комплексов, содержащих во внутренней сфеpe, как анион ацетата, так и молекулу дубителя.

\section{Взаимодействие в системе соли цинка - белок}

Соли цинка характеризуются относительно сильной способностью к комплексообразованию с остатками аминокислот. В работе [11], по результатам исследования связывания металлов для сшивки тройной спирали коллагена и полипептидов, установлено повышение стабильности гомо- и гетеропептидов при добавлении в раствор белка солей цинка, за счет образования связей с боковыми радикалами аминокислот. При этом показано, что устойчивость комплексов увеличивается в ряду ацетат < имидазол < глутатион. Белки являются достаточно сложными системами для исследования взаимодействия с солями цинка, в то же время более пригодными для этой цели являются основные структурные единицы белков - аминокислоты. Аминокислоты являются биолигандами с активными донорными атомами и способны образовывать устойчивые координационные соединения с ионами металлов. Поэтому их можно использовать в качестве модели, позволяющей оценить способность к комплексообразованию тех или иных функциональных групп.

Комплексы цинка с аминокислотами в основном имеют тетраэдрическое строение [13, 14]. Аспарагиновая кислота имеет три потенциальных координационных сайта: аминный азот и две карбоксильные группы, а гибкая структура радикала кислоты способствует ее координации с атомом металла в виде бидентатного или тридентатного лиганда [16]. Можно предположить, что в данном случае возможно образование комплекса двух типов, включающих взаимодействие цинка с атомом кислорода карбоксильной группы и с атомом азота a- аминометильной или амидной группы боково- го радикала аминокислоты. При этом положительный заряд цинка нейтрализуется отрицательными зарядами атомов кислорода в карбоксильных группах, а незаряженные атомы азота аминогрупп образуют координационные связи. При взаимодействии солей цинка с лизином и аспарагиновой кислотой, возможны стерические затруднения, в случае лизина, из-за длинной боковой цепи, заканчивающейся аминогруппой, в случае аспарагиновой кислоты, более удаленной от а- атома азота карбоксильной группы боковой цепи. Вероятно, с этими аминокислотами образование комплексов возможно только по функциональным группам боковых радикалов.Описанные в литературекомплексы цинка с аминокислотами представлены в следующем виде: комплекс с аспарагиновой кислотой [-OOC- $\left.\mathrm{CH}_{2}-\mathrm{CH}\left(\mathrm{NH}_{2}\right)-\mathrm{COO}-\right] \mathrm{Zn} \cdot 2 \mathrm{H}_{2} \mathrm{O}[13,17]$, комплекс с лизином [ $\left.\mathrm{Zn}\left(\mathrm{C}_{6} \mathrm{H}_{14} \mathrm{~N}_{2} \mathrm{O}_{2}\right)_{2}\right] \cdot 2 \mathrm{H}_{2} \mathrm{O}$ [18].

При растворении аминокислот в воде значения $\mathrm{pH}$ этих растворов в основном соответствуют значениям изоэлектрической точки данной аминокислоты. Значения $\mathrm{pH}$ растворов соответствующих изоэлектрическому состоянию аминокислот, используемых в данной работе, составляют [19]: для лизина 9,82; для аспарагина 5,41; для аспарагиновой кислоты 2,77. При определении электропроводности $1 \%$-х растворов этих аминокислот получены следующие значения, соответственно $5,25,4$; 0,64 и $1,37 \mathrm{mS}$. Зависимость удельной электропроводности растворов аминокислот от концентрации является линейной, а электропроводность смеси аминокислоты и соли в растворе в отсутствии химического взаимодействия носит аддитивной характер. На рис. 4 представлены зависимости электропроводности растворов аминокислот от массовой доли солей цинка.

Для растворов лизина и аспарагиновой кислоты (рис. 4 кривые 14) характерны значительные отклонения экспериментальных значений электропроводности от аддитивных значений с увеличением содержания солей цинка. Максимальное отклонение для растворов лизина наблюдается при массовой доле соли цинка $25 \%$, как для сульфата, так и для ацетата. Отклонение от аддитивности свидетельствует о наличии взаимодействий в системе. Поскольку соли цинка и лизин могут взаимодействовать между собой с образованием комплексных соединений, то вполне вероятно, что максимум на кривой соответствует образованию такого комплекса. В этом комплексе цинк может быть координирован с двумя лигандами лизина. Эта структура приводит к образованию положительной катионной группы, с которой связывается ацетат-анион с образованием ионной соли $\left[\mathrm{Zn}\left(\mathrm{C}_{6} \mathrm{H}_{14} \mathrm{~N}_{2} \mathrm{O}_{2}\right)_{2} \mathrm{CH}_{3} \mathrm{COO}\right]^{+} \mathrm{CH}_{3} \mathrm{COO}^{-}$. 


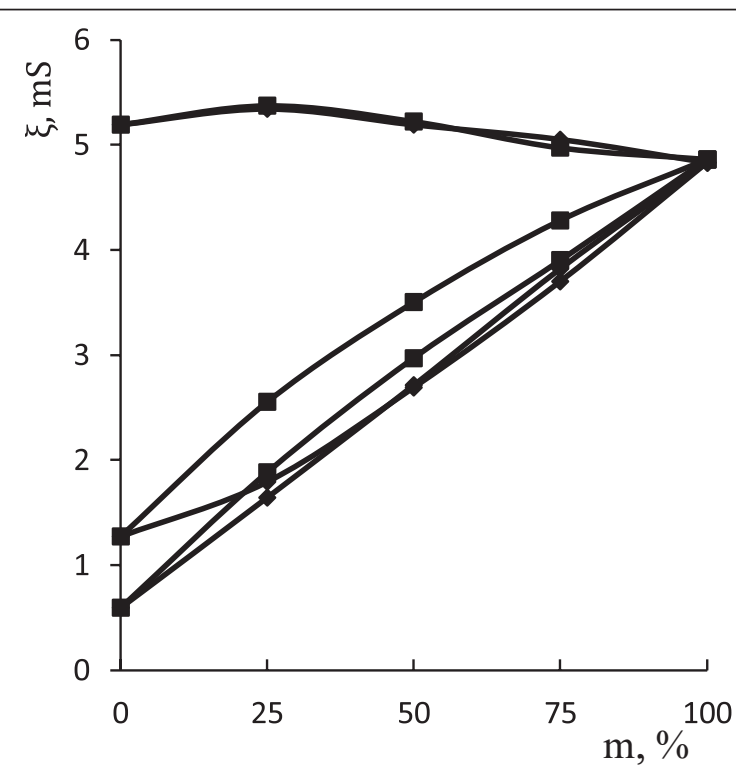

Рис. 4. Влияние массовой доли т сульфата цинка $(1,3,5)$ и ацетата цинка $(2,4,5)$ на электропроводность

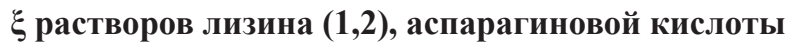
$(3,4)$, аспарагина $(5,6)$

Результаты эксперимента по исследованию влияния массовой доли солей цинка на электропроводность раствора аспарагиновой кислоты свидетельствуют об увеличении этого показателя при более высокой доле соли цинка (рис. 4 кривые 3,4 ). Из представленных данных видно, что для сульфата цинка наблюдается положительное отклонение экспериментальной зависимости электропроводности от расчетной, а в случае ацетата цинка это отклонение отрицательное. Наибольшее отклонение в обоих случаях зафиксировано при массовой доле соли цинка в растворе равное $50 \%$, что свидетельствует об образовании комплекса состава $1: 1$. При этом положительное отклонение электропроводности растворов при введении сульфата цинка может быть связано с вытеснением из внутренней сферы комплекса сульфогруппы, и образованием ионной соли $\left[\mathrm{ZnC}_{4} \mathrm{H}_{7} \mathrm{NO}_{4}\right]^{2+} \mathrm{SO}_{4}{ }^{2-}$.

Учитывая близкие к нейтральным значения изоэлектрической точки растворов аспарагина, и анализируя экспериментальные значения электропроводности растворов при увеличении массовой доли солей цинка, можно сделать вывод о том, что процессы комплексообразования в данном случае проходят по механизму, рассмотренному для аспарагиновой кислоты.

\section{Взаимодействие в системе желатин - органический дубитель - соли ичинка}

При оценке взаимодействия в достаточно сложной системе, в которую входят волокнисто- пористый компонент - дерма шкуры животного, раствор дубителя и раствор соли цинка, в качестве модельного препарата, имитирующего дерму, использовали гель желатина. Такой аналог коллагена дермы применяется в целом ряде работ, посвященных изучению условий реакций коллагена с различными соединениями $[20,21]$. Желатин - наиболее близкий к коллагену по составу и структуре препарат, получаемый при переработке кожевенного сырья [22].

Эксперимент выполняли с использованием целлюлозных диализных мембран, в одну из которых помещали исходный желатин, в другую желатин, предварительно обработанный органическим дубителем. Для удаления низкомолекулярных продуктов из исходного желатина и несвязанного с желатином органического дубителя, контейнер с желатином выдерживали в дистиллированной воде в течение суток. Затем контейнеры помещали в емкости со свежеприготовленными $1 \%$-ми растворами сульфата или ацетата цинка, и фиксировали изменения электропроводности этих растворов.

На рис. 5 представлены зависимости электропроводности растворов солей цинка от продолжительности эксперимента. Более существенное снижение электропроводности отмечено в растворе с сульфатом цинка.

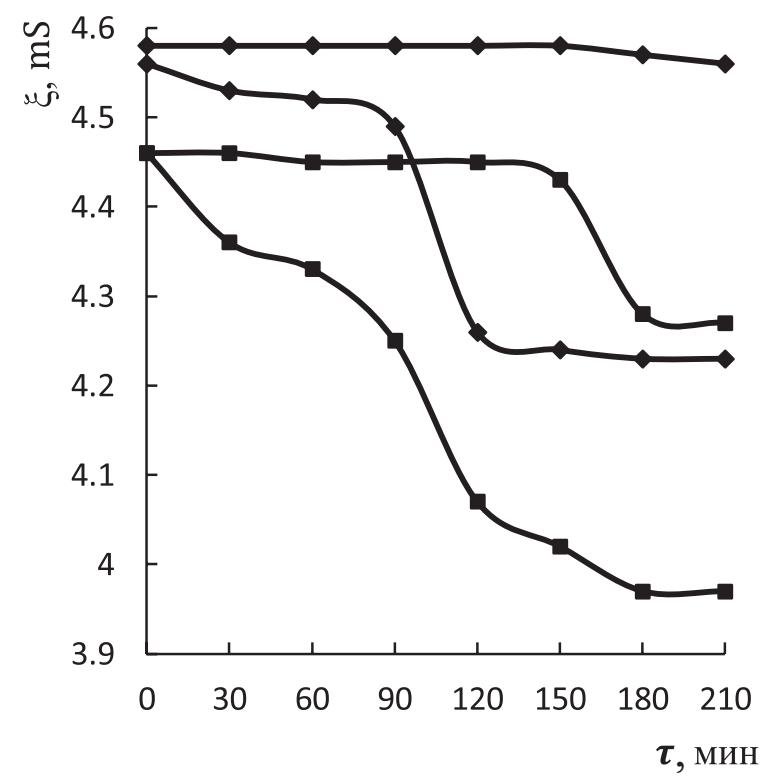

Рис. 5. Изменение электропроводности $\xi$ растворов солей цинка в процессе сорбции ацетата цинка

$(1,2)$ и сульфата цинка $(3,4)$ желатином $(1,3)$ ипродубленным желатином $(2,4)$

Предварительно была установлена линейная зависимость электропроводности растворов 
от концентрации соли цинка в пределах от 0,1 до $1,5 \%$, позволяющая определить сорбцию солей цинка из растворов. Полученные данные свидетельствуют о том, что при равных условиях эксперимента сорбция солей цинка продубленным желатином идет более интенсивно, чем исходным. Исходя из анализа представленных зависимостей (рис. 5), можно сделать вывод, что сорбция сульфата цинка проходит более равномерно во времени, но максимум сорбции, как для сульфата, так и для ацетата цинка, приходится на период времени от полутора до двух часов.

Более интенсивную сорбцию сульфата цинка, в том числе и продубленным желатином можно объяснить меньшим сродством сульфатного лиганда к иону цинка, поэтому он может быть легко заменен во внутренней сфере комплекса молекулой дубителя.

На основании проведенных исследований разработана методика комбинированного дубления кож с использованием солей цинка и органического дубителя Ортан, которая была проверена в экспериментальных условиях на кожевенном предприятии (г. Ярославль). В результате получен светлый полуфабрикат, не содержащий соли хрома, с температурой гидротермической устойчивости не менее $80^{\circ} \mathrm{C}$.

\section{Выводы}

Исследовано взаимодействие солей цинка с органическим дубителем и показана возможность образования комплексных соединений с координацией иона цинка по метилольным группам дубителя и атомам азота. Определены оптимальные соотношения солей цинка и дубителя, обеспечивающие максимальный выход комплексного соединения.

Подтверждено образование комплексных соединений солей цинка с аминокислотами, представленными в структуре коллагена, и показаны наиболее вероятные структуры этих комплексов.

Установлено, что желатин, предварительно обработанный дубителем, способен более эффективно сорбировать соли цинка из растворов. Причем максимальной способностью к сорбции характеризуется сульфат цинка.

Полученные данные приняты во внимание при разработке технологии комбинированного бесхромового дубления с использованием солей цинка и органического дубителя.

\section{Лuтература}

1. Josep M. Morera, Esther Bartoli, Roberto Chico,Cristian Solé, Luisa F. Cabeza. Journal of Cleaner Production.
2011.V. 19. N.17-18. P. 2128-2132.DOI: 10.1016/j. jclepro.2011.07.018.

2. El-Khateeba M.A., El-Shahat H.A. Nashyb, N.A. Abdel Ghanyc, Ahmed M. Awad. Desalination and water treatment. 2017. V. 65. N.3. P. 147-152. DOI: 10.5004/ dwt.2017.20250.

3. Badar M., Saeed M., Batool F. International Journal of Environment, Agriculture and Biotechnology (IJEAB). 2016. V. 1. N.3. P. 559-564. DOI: $10.22161 /$ ijeab/1.3.38.

4. Чурсин В.И. Технологические процессы и экология кожевенного производства: монография. М. ФГБОУ ВО «РГУ им. А.Н.Косыгина». 2019. $161 \mathrm{c.}$

5. Панфилов Е.В., Чурсин В.И. Изв. вузов. Химия и хим. технология. 2019. Т. 62. Вып. 9. С. 110-116. DOI: $10.6060 /$ ivkkt.20196209.5918

6. MubarkYahia, Musa A.E., Gasmelseed G.A., Faki E.F., Ibrahim H.E., Haythem O.A., Manal M.A., Haythem $S . B$. International Journal of Advance Industrial Engineering.2019. V. 7. N. 2. P.104-110. doi.org/10.14741/ ijaie/v.7.2.2.

7. Чурсин В.И., Чиркова Н.А. Изв. вузов. Химия и хим. технология. 2010. Т. 53. Вып. 1. С. 91-93.

8. Saravanabhavan Subramani, Nishad N. Fathima, Jonnalagadda Raghava Rao, Balachandran Unni Nair. Journal Society of Leather Technologists and Chemists. 2004. V. 88. N. 2. P. 76-81.

9. Магомедова П.М., Чурсин В.И. Исследование дубящей способности нейтрализованных органических дубителей. Мат. Х1У межд. научн-практ. конф. Кожа и мех в XX1 веке: технология, качество, экология, образование: Улан-Удэ. ВСГУТУ. 2018. С. 18-26.

10. Shan Cao, Baozhen Cheng, Qiaoe Wang, Bing Liu. Journal American Leather Chemists Association. 2013. V. 108. N. 11. P. 428-433.

11. Avanish S. Parmar, Fei Xu, Douglas H. Pike, Sandeep V. Belure, Nida F. Hasan, Kathryn E. Drzewiecki, David I. Shreiber, Vikas Nanda. Biochemistry. 2015. V. 54. N. 32. P. 4987-4997. doi.org/10.1021/acs.biochem.5b00502.

12. Nadia G. Kandile, Taha M.A. Razek, Ahmed M. AlSabagh, Maamoun M.T. Khattab. Egyptian Journal of Petroleum. 2014. V. 23. N.3. P. 323-329. http://dx.doi. org/10.1016/j.ejpe.2014.08.008.

13. Artur Krężel, Wolfgang Maretb. Arch. Biochem. Biophys. 2016. V. 611. N.1. P. 3-19. doi: 10.1016/j. abb.2016.04.010.

14. Yi-Han Ting, Hsuan-Ju Chen, Wan-Jung Cheng, JiaCherngHorng. Biomacromolecules. 2018. V. 19. N.7. P. 2629-2637. doi.org/10.1021/acs.biomac.8b00247.

15. Шачнева Е.Ю., Зухайраева А.С. Астраханский вестник экологического образования. 2015. №2(32). C. $122-124$.

16. Pinto D., Puppin P.A.L., Behring V.M., Alves O.C., Rey N.A., Felcman J. Inorganica Chimica Acta. 2012. V. 386. N. 5. P. 60-67. doi.org/10.1016/j.ica.2012.01.025.

17. Кадырова Р.Г., Кабиров Г.Ф., Муллахметов Р.Р. Биологические свойства и синтез комплексных солей a-аминокислот биогенных металлов. Казань. Казан. гос.энерг.ун-т. 2014. 108 с.

18. Shaotang Yuan, Shiri Nawrocki, Michael Stranick, Ying Yang, Chong Zheng, James G. Masters, Long Pan. In- 
org. Chem. 2016. V. 55. N.20. P. 10094-10097. doi. org/10.1021/acs.inorgchem.6b01663.

19. Якубке X.-Д., Ешкайт X. Аминокислоты, пептиды, белки. М.: Мир. 1985. 456 С.

20. Sabrina Sobel, Allison Haigney, Tracy Concepcion, Michael Kim. Chemical Speciation and Bioavailability. 2008. V. 20. N.2. P. 93-97. doi. org/10.3184/095422908X322833.
21. Kochańczyk T., Drozd A., Krężel A. Metallomics. 2015. V. 7. N. 2. P. 244-257. doi.org/10.1039/C4MT00094C.

22. Mohamed S.A. Abdel-Mottaleb, Eman H. Ismail. Journal of Chemistry. 2019. V. 23. N. 5. P. 1-18. doi. org/10.1155/2019/3241061.

23. Liu D., Nikoo M., Boran G., Zhou P., Regenstein JM. Annu Rev Food Sci Technol. 2015. V. 6. P. 527-557. doi: 10.1146/annurev-food-031414-111800. 